\title{
Del colegio de caciques al colegio de Granada: la educación problemática de un noble descendiente de los incas
}

Du collège des caciques au collège de Grenade : l'éducation problématique d'un descendant des incas

From the college of caciques to the college of Granada: the problematical education of a noble descendant of the Incas

\section{Monique Alaperrine Bouyer}

\section{(2) OpenEdition}

\section{Journals}

Edición electrónica

URL: http://journals.openedition.org/bifea/7119

DOI: $10.4000 /$ bifea. 7119

ISSN: 2076-5827

Editor

Institut Français d'Études Andines

Edición impresa

Fecha de publicación: 1 diciembre 2001

Paginación: 501-525

ISSN: 0303-7495

Referencia electrónica

Monique Alaperrine Bouyer, « Del colegio de caciques al colegio de Granada: la educación problemática de un noble descendiente de los incas », Bulletin de l'Institut français d'études andines [En línea], 30 (3) | 2001, Publicado el 08 diciembre 2001, consultado el 10 diciembre 2020. URL : http:// journals.openedition.org/bifea/7119; DOI : https://doi.org/10.4000/bifea.7119

\section{(9) $(0 \Theta \Theta$}

Les contenus du Bulletin de l'Institut français d'études andines sont mis à disposition selon les termes de la licence Creative Commons Attribution - Pas d'Utilisation Commerciale - Pas de Modification 4.0 International. 


\title{
DEL COLEGIO DE CACIQUES AL COLEGIO DE GRANADA: LA EDUCACIÓN PROBLEMÁTICA DE UN NOBLE DESCENDIENTE DE LOS INCAS
}

\author{
Monique ALAPERRINE BOUYER*
}

\section{Resumen}

En 1792 Carlos IV funda de forma algo prematura con el fin de controlar el descontento creciente de los criollos, un colegio en España para educar a los nobles americanos. La cédula no excluye a los nobles indígenas. Uno de ellos, D. Bartolomé Mesa Tupac Yupanqui, solicita una beca para su primo Don Santiago Phelipe Camilo Túpac Yupanqui, beca que no le otorga el virrey. Sus diligencias y sus disimulaciones, su terquedad así como los falsos argumentos del virrey dejan ver la atmósfera de recíproca suspición de aquella sociedad peruana todavía marcada por la rebelión indígena de 1780, al mismo tiempo que revela la índole de la palabra real.

Palabras claves: Educación, nobles americanos, colegio de Granada, Incas (descendientes de los), Ilustración, reivindicaciones indígenas.

\section{DU COLLÈGE DES CACIQUES AU COLLÈGE DE GRENADE : L'ÉDUCATION PROBLÉMATIQUE D'UN DESCENDANT DES INCAS}

\section{Résumé}

En 1792 Charles IV, fonde de manière prématurée et afin de contenir le mécontentement croissant des créoles, un collège en Espagne pour les nobles américains. Le décret n'exclut pas les nobles indigènes et l'un d'eux, D. Bartolomé Mesa Tupac Yupanqui, homme cultivé et actif, sollicite l'inscription de son cousin Don Santiago Phelipe Camilo Tupac Yupanqui dont la candidature n'est pas retenue. Ses démarches et ses dissimulations, son opiniâtreté ainsi que les faux arguments du vice-roi laissent percevoir le climat de suspicion réciproque qui régnait dans la société péruvienne encore marquée par la révolte indienne de 1780, en même temps que se révèle la véritable nature de la parole royale.

Mots clés : Éducation, nobles américains, collège de Grenade, Incas (descendant des), Illustration, revendications indigènes.

\section{FROM THE COLLEGE OF CACIQUES TO THE COLLEGE OF GRANADA: THE} PROBLEMATICAL EDUCATION OF A NOBLE DESCENDANT OF THE INCAS

\section{Abstract}

In 1792, Charles IV founded a college in Spain for educating noble Americans. This somewhat premature move aimed at curbing the growing discontent of the criollos. The royal

\footnotetext{
"Université Paris III, Sorbonne Nouvelle: 13 rue de Santeuil,75005 Paris.E-mail: alaperri@ clubinternet.fr
} 
decree did not exclude indigenous nobles. One of them, D. Bartolome Mesa Tupac Yupanqui, asked for a scholarship for his cousin, D. Santiago Phelipe Camilo Tupac Yupanqui. However this scholarship was not granted by the Viceroy. The further actions carried out by D. Bartolome as well as the facts which he concealed, his stubbornness in fighting out his cause as well as the false arguments used by the Viceroy, illustrate the atmosphere of reciprocal suspicion that characterised contemporary Peruvian society still under the effects of the indigenous rebellion of 1780. At the same time it makes manifest the dubious nature of the royal intentions.

Key words: Education, American nobles, the college of Granada, Incas (descendants of) enlightenment, indigenous claims.

La educación de los súbditos americanos fue para la Corona española objeto de constantes preocupaciones que dieron lugar a múltiples cédulas. Relativamente pronto se fundaron universidades y colegios mayores con vistas a la formación de las élites y, mal que bien en el Perú de principios del XVII, dos colegios destinados a los hijos de caciques que no podían mezclarse con los nobles peninsulares y criollos. Los jesuitas se encargaron de ellos desde 1619 hasta su expulsión —bajo el gobierno del virrey Amat, reinando Carlos III - al mismo tiempo que asumían la educación de buena parte de las élites españolas y criollas.

Los Borbones, en su empresa de reorganización de la administración de las colonias también se preocuparon por la educación y formación de las élites americanas. La labor pedagógica de los jesuitas, largamente considerada como la mejor, fue criticada. La ilustración penetró en América y las ideas nuevas llevadas por el viento que soplaba desde América del Norte y desde Francia se hicieron camino a pesar de la censura.

En 1792 Carlos IV, aconsejado por el conde de Floridablanca y "habiendo observado que nada importa tanto como la universal difusión de las luces, y que de ningún modo puede ésta asegurarse sino perfeccionando el sistema de conocimientos humanos en la generación creciente y en las que la han de suceder", fundaba un colegio en España para la educación exclusiva de los nobles americanos sin distinción, estableciendo unas constituciones de 47 artículos (A.G.I., Indiferente general 1620) (1).

Los primeros estudios sobre este colegio fueron en 1962-1963 los de Richard Konetzke y del padre Olaechea Labayen. El primero había publicado, ya diez años antes, una parte de las constituciones; en cuanto al segundo, ofrece una síntesis de los documentos contenidos en tres legajos del Archivo de Indias de Sevilla, añadiendo un apéndice documental sobre el establecimiento del colegio y la reproducción entera de la real cédula de 1792. Más tarde, José Luis Barea Ferrer tocó el tema en un trabajo sobre el palacio de Carlos V en 1793 (1977-1978), esencialmente desde un punto de vista de la historia militar y del monumento. María Lourdes Díaz Trechuelo (1972), Marie Laure Rieu Millan (1982) y María Magdalena Guerrero Cano (1996-1997) también lo tocaron siguiendo las pistas de los criollos americanos que vinieron a España al colegio de Granada, cumpliendo con los requisitos de la cédula real.

(1) Esta real cédula con las constituciones ha sido publicada por el padre Olaechea Labayen, 1963. También por Eguiguren, s.f.: 339, y en parte por Konetzke, 1953, vol. III. 
Todos estos estudios se centran esencialmente en los nobles criollos para quienes el proyecto había sido elaborado en prioridad, dando poco espacio, o ninguno, a los otros nobles americanos: los indios descendientes de los incas que desde una real cédula de 1545 gozaban de títulos y privilegios de nobleza. Sin embargo, la posible candidatura a fines del siglo XVIII de esta nobleza que intentaba a duras penas conservar sus prerrogativas, presenta un interés ya que permite ver qué lugar las élites indígenas pudieron ocupar en el ambiente de las reformas educativas.

\section{DE LOS SEMINARIOS DE NOBLES AL COLEGIO DE NOBLES AMERICANOS DE GRANADA}

El proyecto de crear un colegio especial para los nobles americanos resultó del fracaso de otro: el de atraer a España a los hijos de la aristocracia de ultramar que se sentía postergada en las funciones administrativas y militares y cuyo descontento ya era manifiesto. La uniformidad de la enseñanza practicada durante dos siglos particularmente por la Compañía, de insigne reputación, pero también por otras órdenes religiosas, en todas las provincias de la monarquía española, había mantenido esta élite en la ilusión de una igualdad de oportunidades y derechos con los peninsulares a pretender altos puestos, al mismo tiempo que la pedagogía se iba quedando invariable y uniforme (Gonzalbo Aizpuru, 1989: 229).

Un seminario de nobles había sido creado por Felipe V en 1725 en Madrid, destinado a la educación de la nobleza española en las cuatro carreras: eclesiástica, militar, de gobierno y de justicia, y más tarde otro en Valencia, los dos dirigidos por los jesuitas al principio. Carlos III, aconsejado por el futuro conde de Floridablanca quiso atraer allí a los nobles americanos. Muy pocos se manifestaron, ni aun cuando se les reservó una cuota de cuarenta plazas (2). Juan B. Olaechea nota que buena parte de los fondos económicos de este colegio provenían de América y que por tanto era justo que los americanos gozasen de la educación que en él se dispensaba. La nobleza americana sin embargo no pareció compartir esta opinión. Entonces Carlos IV dio un paso más, en 1792, con la creación del Colegio Mayor para Nobles Americanos de Granada (Olaechea Labayen, 1963: 212-213).

Los seminarios de nobles dispensaban bajo Carlos III y Carlos IV una enseñanza moderna dando cada vez más espacio a las llamadas ciencias útiles además de las letras y de una filosofía más abierta, como lo atestiguan ciertos certámenes que fueron publicados (3). Algunos nobles indios habían sido alumnos del Seminario de Nobles de Madrid, al parecer obedeciendo los mismos designios reales de control que los alejaban

(2) Una nota de José Galvez al conde de Floridablanca (11/8/1784) dice: “que de no señalarse un número de plazas hará poco o ningún efecto en Indias porque allá saven que siempre han sido admitidos los pocos que han venido al colegio" (Indiferente general 1619).

(3) Certamen oratorio-poético, en el qual los señores colegiales del seminario de nobles de San Ignacio... con los alumnos de las escuelas que la... ciudad de Valencia instituyó en dicho seminario... Valencia, 1745, o Felipe WARD, Certamen público de los tratados de matemáticas, geometría sublime y mecánica que en el Real Seminario de Nobles tendrá el caballero seminarista D. Felipe Ward.. 
de América. Entre ellos don Manuel y don Dionisio Uchu Inca Túpac Yupanqui, hijos de don Domingo Uchu Inca Túpac Yupanqui, alférez de la compañía de Infantería del Presidio del Callao. Éste vino a España con sus dos hijos “de orden de S.M. comunicada al virrey que fue del Perú don manuel de Amat", posiblemente en 1767, ya que un documento de enero de 1768 (A.G.I., Indiferente general 1613, fol. 6) le concede una pensión "sin permitir a uno ni a otro su regresso a la América por dictarlo assí la prudencia y la política", lo que supone una fuerte sospecha de rebelión. No tenemos otra precisión a su respecto sino que "se le mandó pasar de aquellos a estos reynos cuio viaje verificó con la mayor resignación y conformidad..." (A.G.I., Indiferente General 1613) (4). Cabe suponer que perteneciera a lo que John Rowe llama "la fase preparativa del tercer ciclo" de rebeliones (1954: 22). Mucho más tarde, don Dionisio sería uno de los cinco suplentes elegidos en Cádiz para representar el Perú en las Cortes, allí se distinguiría por sus discursos extremistas y en favor de los indígenas. Fue un ardiente defensor de la supresión del tributo, pidió que las prebendas fuesen reservadas a los naturales y expuso delante de los diputados una visión muy negativa de la Conquista (Rieu Millan, 1990: 75, 110, 121, 165).

Sin embargo algunos nobles indios podían pretender de su propia voluntad una plaza en estos seminarios. La posibilidad de compartir una misma enseñanza con los nobles peninsulares o criollos era para ellos la oportunidad de afirmar la igualdad que venían reivindicando desde los principios de la conquista y esto podía atraer a los que se consideraban injustamente "abatidos", como se nota en el caso de Doña María Joaquina Inca que en una de sus numerosas solicitudes pide dinero para que su marido vaya a España con su hijo "para que su Magestad lo ponga en el seminario o en donde sea más de su real agrado" (A.G.I., Mexico 2346). El caso es que sólo consiguió una beca en el colegio de San Juan de Letrán en México, colegio fundado para mestizos. Al parecer Doña María Joachina no ofrecía ningún peligro para la corona española, y como carecía de los necesarios recursos económicos no podía mandar sus hijos a España aunque lo anhelaba.

\section{UN PROYECTO POLÍTICO DEL DESPOTISMO ILUSTRADO}

Las razones que da el rey por la erección de un colegio reservado exclusivamente a los nobles americanos son que:

"por su cercanía, [le] proporcione mayor facilidad de certificar[se] de su mérito para emplearlos, así en España como en América, en todas las carreras a que se hagan acreedores con su aplicación y conducta".

Se trataba pues de instaurar una paridad entre nobles americanos y nobles peninsulares en la medida en que, según este proyecto, el flujo de altos funcionarios ya no se haría en sentido único: los peninsulares siendo los que iban a América a desempeñar altos cargos, sino que los americanos en adelante vendrían a España a lo mismo. El proyecto presentado por un capuchino, fray Josef de Montealegre al conde de Floridablanca, permitía desarmar el descontento de la aristocracia americana:

(4) Solicitud de Don Manuel y Don Dionisio Uchu Ynca a la muerte de su padre en 1784. 
"manifestando que el medio más suave y conducente a conservar fieles los dominios de Indias era establecer en España un Colegio Mayor de Nobles Americanos con la promesa de conferir a sus individuos en cada Audiencia una toga, en cada Cabildo un canonicato y en cada regimiento una compañía..." (5)

El rey aprobó este proyecto excepto la destinación de los alumnos al salir del colegio, le pareció más prudente que no volvieran a su tierra (6). Más que puro producto de la Ilustración, el Colegio Mayor de Nobles Americanos era pues una medida política de prevención, que llevaba tiempo germinando entre los consejeros reales. En efecto, en un consejo extraordinario presidido por Aranda en 1768, los fiscales entre los cuales estaba José Moñino, el futuro conde de Floridablanca, habían informado ya al rey sobre la necesidad de prevenir el espíritu de rebelión (Barea Ferrer, 1977-1978: 34).

“...Urge en el día más, atraer a los americanos por causa de estudios a España formando un establecimiento honroso y lucido con este fin; darles en la tropa un número determinado de plazas; tener algún regimiento de naturales de aquellos países dentro de la Península, y guardar la política de enviar siempre españoles a Indias con los principales cargos ..."

Sin embargo la idea tardó veinticuatro años en tomar la forma de un real decreto.

\section{UN PROYECTO QUE NO CUAJÓ}

Este colegio o seminario estaría en Granada, ciudad elegida por su situación geográfica y la templanza de su clima. Su financiación, al principio, se sacaría del fondo de Temporalidades para luego estar a cargo de las familias americanas. Se eligió como lugar el palacio de Carlos V en la Alhambra pero este palacio, todavía sin acabar, suponía muchas obras costosas y mientras se realizasen, el colegio estaría en el antiguo colegio de Santa Catalina que también necesitaba refección.

En realidad, el decreto salió de manera muy prematura y cuando llegaron los primeros jóvenes nada estaba previsto para acogerlos. Unos que habían salido del Perú tuvieron un viaje lleno de vicisitudes debidas a una tempestad y a la piratería inglesa y tuvieron que contentarse con soluciones improvisadas que incluso tardaron en encontrarse (7). Las obras, la financiación, son los obstáculos que se mencionan para explicar el fracaso del colegio de Nobles Americanos de Granada que nunca llegó a funcionar, pero detrás de los pretextos económicos muchas veces se esconden otros motivos más políticos: entre los documentos de Sevilla un informe de 1794 dice que la ciudad de Málaga, solicitada para acoger a los estudiantes se negó a hacerlo, y el mismo

(5) A.G.I., Indiferente general, 1620, publicado por Olaechea Labayen, 1963: 219. Olaechea relaciona la fecha de la representación del capuchino — 25 de octubre de 1789—, con la revolución francesa.

(6) El caso de Don Antonio Villavicencio (el protomártir de la Independencia de Colombia) que sus padres enviaron a estudiar en el colegio de Nobles Americanos, daría luego razón al rey.

(7) "Han llegado estos jóvenes en noviembre del año pasado después de haber padecido la más lamentable suerte en su navegación y perdido quanto trahían en la Fragata de comercio el Aquiles apresada por los enemigos..." (A.G.I., Indiferente general 1620). 
documento alude a otro informe anterior de un ministro del Consejo y Cámara de Castilla que se oponía lacónica y claramente al proyecto sin argumentar (A.G.I., Indiferente General 1621). Esto evidencia la oposición de toda una parte de la clase política española al respecto, debida a la imagen negativa que se tenía en España de los criollos (Lavallé, 1993). En abril de 1795 se puso un término a las admisiones decidiendo que los jóvenes se repartirían en los diferentes colegios de Granada. Pero desde 1793, incluso antes, como vamos a verlo con la solicitud de don Camilo Túpac Yupanqui, los jóvenes americanos habían estado mobilizados.

Los americanos, en efecto, habían reaccionado rápidamente a favor de este proyecto tanto más cuanto que el rey ofrecía dos becas de gracia para cada reino. La cédula se publicó en el Perú en dos números del Mercurio Peruano del 26 y 30 de agosto de 1792.

Desgraciadamente no queda una lista completa de los jóvenes que se fueron a España, sólo constan las solicitudes de los que pedían una beca y de algunos que al llegar se encontraron sin colegio. Hubo jóvenes a quienes sus padres mandaron a Granada, costeando el viaje, sin pretender una beca. Poco rastro queda de ellos. Por otra parte, las becas no se otorgaron a los más necesitados sino que, siendo consideradas como un favor personal del rey, fueron solicitadas en prioridad por los más altos y más influyentes personajes.

Las condiciones de admisión eran: ser noble, sin excluir a los hijos de caciques y nobles indios, lo que instauraba una vez más oficial y teóricamente una igualdad entre unos y otros, igualdad constantemente reivindicada por los indios y que les era denegada en la realidad por los criollos y la administración colonial. Los alumnos debían tener entre doce y diez y ocho años y estar instruidos en latinidad. Los candidatos tenían la obligación de probar ante el virrey su nobleza y la limpieza de sangre de sus padres y abuelos por copias legalizadas de ejecutorias de hidalguía ganadas en tribunal competente con el cumplimiento dado por las justicias de los pueblos respectivos. También se les exigía ser robustos y estar en perfecta salud.

En cuanto a las becas, se dispuso que se costearían enteramente la habilitación y pasaje a España de los dos primeros jóvenes que vinieran de cada uno de los virreinatos, por cuenta de los fondos del colegio, regulándose por las fechas de la presentación de los memoriales la prioridad de las pretensiones, "y en caso de presentarse varios en un mismo día decidirá la suerte".

Los estudios constarían, al principio, de las ciencias preliminares o auxiliares de la futura profesión, un examen permitiría admitir a los colegiales al estudio de la teología, de la jurisprudencia, de la política o del arte militar para que nadie "sin culpa suya pueda dejar de hacer progresos rápidos en su carrera."

En resumidas cuentas se trataba de dar a cada uno la misma oportunidad de lograr graduarse en las mejores condiciones fuese cual fuere su nivel de conocimientos a su llegada. Se nota pues por parte del rey en estas constituciones una reiterada preocupación por la igualdad de sus súbditos nobles. Además se enseñarían las lenguas vivas más usuales en Europa, la equitación y el baile, salvo para los teólogos, y se insiste en la necesidad de relacionar las diferentes ciencias entre sí, que los jóvenes entiendan su encadenamiento, ideas éstas que se habían desarrollado en la segunda parte del siglo 
XVII (véase Sor Juana Inés de la Cruz, Respuesta a Sor Filotea de la Cruz). No hay más precisiones sobre las ciencias que se enseñarían allí, pero como ya las Matemáticas, la Física experimental, la Historia y la Náutica, ciencias "útiles" se enseñaban en el seminario de nobles de Madrid, parece implícito que también los colegiales de Granada habían de gozar de estos adelantos pedagógicos de la época.

Los catedráticos serían nombrados por el rey, los estudios durarían diez años. Así mismo se definen los vestidos (uniformes al estilo de la Corte), la comida, (abundante, sana, sin delicadeza pero con mucho aseo) y el buen trato de los alumnos, todo cuanto contribuía a la imagen de un establecimiento "honroso y lucido" tal como lo había preconizado el capuchino Montealegre.

Entre los que pretendieron una beca en el Perú estaba un noble indio: don Camilo Felipe Túpac Yupanqui, también llamado don Felipe Santiago Camilo Túpac Inca cuya petición fue presentada por su primo don Bartolomé Mesa Túpac Yupanqui. Su caso parece digno de ser comentado, ya que a través de él se perciben varios aspectos de la sociedad colonial de este fin de siglo XVIII, de las redes de poder y de las relaciones entre indios y criollos.

\section{ENTRE EL REY Y EL VIRREY: LA NOBLEZA INDIA}

En 1767 la Nación indiana del Perú (8), por la persona de sus dos procuradores, D. Alberto Chosop y D. Joseph Santiago Ruiz, obsequiaba al virrey Amat la publicación de la Real cédula despachada en 11 de septiembre de 1766 por Carlos III

"mandando a los virreyes, audiencias, gobernadores, arzobispos y obispos de las Indias cuiden con particular atención de que sean admitidos en las Religiones, educados en los colegios, y promovidos según su mérito y capacidad a las dignidades eclesiásticas y oficios públicos".

El virrey Amat promulgó esta cédula en Lima, en junio de 1767, y algunos ejemplares fueron tirados entonces. La nación indiana

"pide y suplica se le conceda licencia para reimprimir a su costa los mencionados despachos, y para que se tiren de ellos, igualmente que del bando publicado, las copias que fueren suficientes a hacer en todo el Reyno notoria la Benignidad del Rey, la justificación de V.E. y nuestra debida gratitud."

Tal obsequio muestra la preocupación de la élite indígena por dar a conocer esta cédula real que repetía dos cédulas anteriores: una de 1691 y otra de 1725 "que si en esa corte se expidieron, en estas Indias jamas se publicaron" (9).

(8) Agradezco a César Itier el haberme comunicado el documento que está en el Archivo de la Biblioteca Americana de B. Mitre, Buenos Aires.

(9) "Representación verdadera y exclamación rendida y lamentable que toda la Nación Indiana hace a la Majestad del Señor Rey de las Españas y Emperador de las Indias, el Señor Don Fernando VI pidiendo los atienda y remedie, sacándolos del afrentoso vituperio y oprobio en que están de doscientos años" publicado por Bernales Ballesteros, 1969: 30. 
La repetición de las cédulas basta por sí sola como prueba de que no se cumplían y por tanto se puede considerar dicho obsequio como un acto político que recordara al virrey sus deberes para con la educación e integración de la nación indiana y la necesidad de informar todo el reino al respecto para que logre efecto.

Cuando en 1792 Carlos IV por otra cédula real crea el seminario de nobles americanos de Granada los indios atentos a sus derechos no desconocen el punto $n^{\circ} 2$ :

"Se admitirán como colegiales los hijos y descendientes de puros Españoles Nobles, nacidos en las Indias, y los de Ministros Togados, Intendentes y Oficiales Militares naturales de aquellos dominios, sin excluir los hijos de caciques, e indios nobles, ni los mestizos Nobles, esto es, de Indio Noble y Española, o de Español Noble e India Noble, conforme al mérito y servicios particulares que sus padres hubieren hecho al Estado".

Tampoco se desentienden de las condiciones de obtención de las becas.

La cédula real, anunciada en el Mercurio Peruano del 23 de agosto de 1792, fue publicada en dos entregas: una en el número 171 del 26 de agosto y la otra al día siguiente. Don Bartolomé Mesa Inca Yupanqui que se ha enterado del artículo $n^{\circ} 8$, el cual concede becas a los dos primeros jóvenes que se alisten en cada reino y del $n^{\circ} 9$ que otorga la prioridad por las fechas de la presentación de los memoriales, no espera ni siquiera la entrega siguiente y viene a presentar una solicitud en nombre de su primo, don Felipe Camilo Túpac Yupanqui, cacique de San Gerónimo (provincia de Jauja). Toma la precaución de hacer escribir arriba y a la derecha del documento lo siguiente: "Se presentó con cargo oy veinte y siete de agosto de noventa y dos a las diez del día" con firma de Sanchez Fernández. En su solicitud dice que habiéndose enterado de la merced real y "hallándose con un primo en quien concurren todos los requisitos que exigen los objetos que se proponen por el soberano no puede menos que interponer este recurso a fin de que el citado primo sea colocado entre aquellos dos primeros jóvenes..." también declara que el joven fue alumno del colegio del Príncipe "donde estudió las primeras letras tan perfectamente que logró aprovación no sólo de todos sus maestros si también del Rector que lo certifica" y que actualmente está en el Real Convictorio de San Carlos.

Dos certificados de dos médicos al parecer eminentes: uno es don Mariano Aguilar, Décano de la facultad y el otro don Thomás Ortigoso, cirujano del hospital de San Andrés, dicen haber reconocido a don Felipe Camilo Tupayupanqui, colegial del real convictorio de San Carlos y dan fe de su robustez y buena salud, uno fechado en 26 de agosto y otro en 27 . Estos dos certificados obedecen al $5^{\circ}$ artículo de la cédula real.

Otro certificado confirma que:

"Don CamiloTúpacyupanqui ha seguido en sobredicho colegio [Santo Tomás] el estudio de la phylosophía en todas sus partes habiendo completado su curso con suficiente aprovechamiento a que dio prueba en un acto público que sustentó por la mañana y por la tarde a presencia de los maestros y estudiantes de las escuelas y casas de estudios de esta ciudad haciendo cada uno sus réplicas correspondientes a que dio el sustentante 
la devida satisfacción con aplauso del concurso y crédito de su habilidad y deseo de su aprovechamiento y para que conste donde le convenga este título di la presente firma de mi nombre en el sobredicho colegio del angélico doctor Santo Tomás de Lima del orden de Predicadores en treinta de abril de 1792. Fray Cipriano Cavallero, Maestro Rector”.

\section{DON BARTOLOMÉ MESA TÚPAC YUPANQUI}

Don Bartolomé Mesa se presenta como "del comercio de esta ciudad” (10). No cabe duda de que es un hombre bien introducido; si no, ¿cómo explicar que haya obtenido tan rápidamente los certificados? En otros documentos (A.G.I., Secretaría de guerra 7104 expediente 27) (11) declara ser descendiente del "gran Túpac Yupanqui" y del conquistador Alonso de Mesa. Cabe recordar que, al final del siglo XVIII, al mismo tiempo que se sigue desarrollando entre los criollos un fuerte sentimiento americanista, se exalta el pasado inca y sus grandezas. El Diario Erudito y Elmercurio Peruano hacen, en varios artículos, el elogio de los peruanos exaltando particularmente al "gran" Túpac Yupanqui y marcando una continuidad entre los tiempos precoloniales y la actualidad, por tanto, poder declararse descendiente del famoso Inca no carece de interés en el trato con los criollos (12).

Parece don Bartolomé Mesa tener vínculos con la Universidad de San Marcos, en particular con el convictorio carolino, al que se refiere varias veces, y con el colegio de caciques. En 1790 costea la publicación de un "Lamento métrico general” (Eguiguren, s.f., 294) que se había compuesto para las excequias del rey Carlos III en agosto del año anterior. Después de una octava en nombre de la Universidad, el real Colegio de San Carlos llora la muerte del rey: "De Carlos el Colegio, llora a Carlos". Esta publicación salió con la aprobación del Dr D. Joseph Baquijano y Carrillo, profesor de ambos derechos de la Universidad de San Marcos, conocido por sus sentimientos americanistas y más tarde por su marcada inclinación por las ideas emancipadoras. El mismo año de 1790 también apareció don Bartolomé Mesa como comisario de la Nación Indica en las fiestas de la Real proclamación de Carlos IV e hizo publicar, otra vez a su costa, las poesías que se compusieron "en tan feliz motivo" para acompañar los cuatro carros y la máscara con que dicha nación lo celebró. La publicación concluye con unas décimas, "Un apasionado de don Bartolomé Mesa" (Medina, 1904, tomo III: 205). Otra impresión con el título de: "El sol en el medio día..." lleva su retrato grabado en cobre (Medina, 1904, tomo III: 210). En noviembre de 1792 un decreto del virrey a propósito de un auto de la junta de aplicaciones de Temporalidades, que atañe al colegio de caciques del Cercado de Lima, menciona a don Bartolomé Mesa y al señor Fiscal Protector como

(10) En la publicación del Lamento métrico se presenta como comerciante almacenista (Eguiguren, s.f.: 286).

(11) Pide grado de coronel de las milicias de infantería de Naturales de Lima en 1795 y declara ser $5^{\circ}$ nieto de Don Alonso Tito Atauchi hijo del emperador Huayna Cápac.

(12) En lo que toca a la continuidad de los reyes del Perú, véase Rowe, 1955: 6-7. Véase también, sobre la relación entre criollos e indios a partir de la rebelión de Túpac Amaru, Mendez, 1993: 25 y 31 . 
personas consultadas al respecto, lo que comprueba el estatus relativamente prominente de aquél y sus vínculos con el colegio del Príncipe (Revista Inca I, 1923: 853). Sin embargo no queda huella de él como alumno de dicho colegio.

Con todo, en 1795, siendo teniente, pidió grado de Coronel de milicias de Infantería de Naturales de Lima (A.G.I., Secretaria de guerra, 7104) lo que le fue negado con pretexto de que:

"Mesa aunque se llame y sea comerciante, es un mercader en la práctica, que vende géneros en su tienda y sería una cosa muy rara que condecorado con un grado a quien V.M. distingue tanto, se viese después detrás de su mostrador abatido baxando piezas de efectos y vareándolas a la voluntad del negro, del zambo y del mulato que van a comprarle. En cuya atención juzga Aviles que no se ha de conceder a Mesa la gracia que pretende, Gil piensa lo mismo..."

Con estos argumentos de desprecio, se niegan a otorgarle el grado superior que entre los comerciantes era tan codiciado como signo de pertenencia a las élites (O'Phelan, 1995: 82). También le reprochan sus pocas proezas militares, añadiendo que si él obtuviese el grado que pide, muchos caciques más meritantes podrían reclamarlo (13).

Estos documentos aunque fragmentarios permiten esbozar el retrato de un noble descendiente de los incas, que a fines del XVIII se reivindica como tal (14), y como tal frecuenta una parte de la nobleza criolla, la más ilustrada, tal vez la más opuesta al poder virreinal. Es un hombre culto, orgulloso, rico, activo, que tiene contactos con diversos sectores de la sociedad limeña, particularmente el de los letrados y de la universidad, muy posiblemente conoció y trató con don Joseph Baquijano y Carrillo, insigne figura de San Marcos que había sido Protector de los Naturales. Padece sin embargo de la acostumbrada discriminación. Si su nombre aparece, es amputado de la parte inca, en publicaciones panegíricas que él mismo costea. Por lo visto, no cuenta con apoyos en la esfera gubernamental.

La candidatura de don Felipe Camilo Túpac Yupanqui permite pues algunas reflexiones sobre las relaciones entre élites criollas y élites indígenas en el Perú a fines del siglo XVIII. Desgraciadamente es la única de que disponemos: no hay otra solicitud de indios nobles para una beca del seminario de Nobles Americanos entre los documentos disponibles hasta la fecha. Al parecer no hubo otra. En realidad eran relativamente pocos los descendientes de Moctezuma y de los incas en edad de concurrir. Pero la cédula real no excluía a los hijos de caciques, más numerosos y, según los documentos, no se presentó ninguno.

Lo que se percibe a primera vista es que los nobles indígenas quedaban atentos a las cédulas reales, más confiados en el lejano monarca que en los diferentes virreyes

(13) A.G.I., Gil , aunque sorprende, no podía ser otro que el entonces virrey fr. Gil de Taboada que solía firmar muchos documentos oficiales de esta forma lacónica.

(14) Su tatarabuelo Alonso de Mesa, fue uno de los contados conquistadores que se casaron con indias. Su mujer legítima fue doña Catalina Guaco Ocllo y declara en su testamento querer reposar a su lado en el convento de la Merced (1587) (Archivo Nacional de Santiago de Chile, Fondo jesuita del Perú, vol. 372). 
que no cumplían y deseosos de alcanzar la mejor educación posible para sus hijos y parientes.

La precaución de don Bartolomé Mesa que consiste en precisar fecha y hora con firma del funcionario en el documento se puede relacionar con la de los dos procuradores de la nación india al publicar, sin reparar en gastos, la cédula real: son actos de desconfianza.

\section{EL ARBITRIO DEL VIRREY ¿DISCRIMINACIÓN O JUSTICIA?}

Ahora bien, tal desconfianza se justificaba, ya que se puede leer al margen de la solicitud de don Bartolomé la decisión del virrey: "Lima y agosto 29 de 1792, respecto de hallarse destinados los jóvenes que deven dirigirse al nuevo colegio que el suplicante expresa, no ha lugar lo que solicita".

En realidad los dos jóvenes designados por el virrey fueron: 1) don Domingo Encalada y Zevallos hijo del conde de la Dehesa, pariente del oidor don Ambrosio Cerdán, aceptado el 20 de marzo de 1793, si bien no fue él quien obtuvo finalmente la beca, y 2) don Pedro Cayetano Fernández Maldonado, hijo del cónsul más antiguo del Real Tribunal del Consulado de Lima, también pariente del oidor, aceptado como becario el 7 de noviembre de 1793. Como se ve, las decisiones fueron tomadas más de un año después de la mención tan cuidadosamente hecha al margen de la solicitud de don Bartolomé Mesa — 27 de agosto de 1792—, lo cual pone de manifiesto que se pasó por alto la fecha de su presentación porque de antemano ésta se rechazaba y el virrey no otorgaba ninguna importancia a dicha mención. Hasta se puede dudar de la veracidad de la fecha del 29 de agosto de la decisión negativa.

Cabe añadir que otro documento del mismo expediente y firma, fechado en marzo de 1794, dice lo siguiente:

"Don Ambrosio Cerdán, ministro togado de la Real Audiencia de Lima se determinó a enviar sus dos hijos don Dionisio y don Ambrosio a $\mathrm{d}(\mathrm{ic})$ ho colegio [de Granada] habiendo obtenido para uno de ellos una de las dos becas de gracia creadas por S.M. a beneficio de aquellos naturales..."

No se precisa en qué circunstancias se cambió la destinación de la primera beca. Basta con notar que quien se benefició de este cambio, si ya no era el pariente, era el propio hijo del oidor, uno de los personajes más importantes del Perú, español ilustrado, miembro de la Sociedad de Amigos o Amantes del País, presidente algún tiempo de ella, miembro de la Real Academia española de Historia (Eguiguren, s.f., 704), muy cercano de Baquijano Carrillo y de Rodríguez de Mendoza, y cuyos hijos estudiaron en el convictorio carolino. También es de subrayar que su memorial había sido apoyado por el virrey en una carta a don Pedro de Acuña, encargado de estos asuntos (A.G.I., Indiferente General, 1620 carta fechada en 26 de octubre de 1793) (15).

(15) Cabe notar que además Don Ambrosio Cerdán beneficiaba del apoyo de un tío oidor de Asturias y de un hermano de éste, capitán de la guardia real. Su abuelo Don Simón Portero había sido miembro del Consejo Supremo de Castilla y su padre oidor. 
En realidad la oportunidad que se ofrecía a los nobles americanos debía ser, en la mente de los dirigentes, exclusivamente la de los criollos que se consideraban superiores a los indios. Don Bartolomé Mesa lo sabía perfectamente y por esto intentó recurrir al Rey. En una carta fechada en Madrid a 7 de mayo de 1793 que, por su tono y contenido, parece digna de ser reproducida aquí, protesta de la manera siguiente (A.G.I., Indiferente General, 1621) (16):

"Don Bartolomé de Mesa Túpac Yupanqui Inca teniente de una de las compañías del Regimiento de Milicias de Naturales de la ciudad de Lima a los R. P. de V.M. con la mayor veneración expone: que habiéndose dignado V.M. crear en la ciudad de Granada un colegio de nobles americanos por su R(ea)l cédula de 15 de enero de 1792 con el objeto de promover y mejorar la educación civil y literaria de la juventud de aquellos dominios remotos e Yslas Filipinas para que así pueda servir útilmente a la Yglesia, la Magistratura, la Milicia y los empleos políticos; creyó ser la ocasión más oportuna y favorable de aprovechar las felices disposiciones de su Primo Santiago Phelipe Camilo Túpac Yupanqui, el qual después de haber aprendido las primeras letras y la latinidad con general aprobación de sus maestros en el colegio del Príncipe se dedicó al estudio de la Filosofia, completando su curso en el Real Convictorio de San Carlos y dando en un acto público que defendió las pruebas más señaladas de su aplicación y aprovechamiento.

Sin embargo de estos útiles progresos no podía mirar con indiferencia el exponente la ventajosa proporción que se le ofrecía para substituir a los antiguos conocimientos de una filosofía caprichosa y llena de sutilezas vanas los buenos y sólidos principios de los Estudios modernos que por consecuencia de la ilustración general han transformado felizmente todo el sistema de la literatura. Movido de tan Digno y laudable zelo luego que se dio al público el contenido de la d(ic)ha cédula en los Mercurios Peruanos de 26 y 30 de agosto del mismo año que a este propio intento acompaña, ocurrió en 27 del propio mes al vuestro virrey del Perú y en conformidad de los articulos $4^{\circ}$ y $5^{\circ}$ de la cédula de erección pretendió una de las dos plazas destinadas para el distrito de aquel virreynato acompañando a este efecto las adjuntas certificaciones señaladas con los $\mathrm{n}^{\circ} 1$ y 2 por las quales constan los adelantamientos de su primo en el estudio de la Filososfia y su buena salud y temperamento robusto. Y si bien omitió exhibir los documentos justificativos de su Nobleza fue por hallarse presentados de antemano en el superior gobierno quando entró en el colegio del Príncipe y por ser notoria su ilustre calidad.

Estas sólidas consideraciones unidas a la particular circunstancia de haber sido el primero que se adelantó a participar de las ventajas del nuevo establecimiento literario, le ofrecían desde luego una lisonjera esperanza

(16) Lo subrayado en cursiva es mío y corresponde a los puntos de la argumentación que serán desarrollados. 
de ser atendida su solicitud y obtenida para su Primo la gracia a que le contemplaba acrehedor. Pero no pensó así el virrey de Lima, porque erigiéndose en árbitro y dispensador de tales nombramientos contra lo expresadamente mandado, decretó en 29 de d(ic)ho mes de agosto el memorial declarando no haber lugar a la pretensión del exponente respecto a hallarse destinguidos los jóvenes que debían dirigirse al nuevo colegio, como lo acredita el mismo memorial y Decreto original que acompaña con el $n^{\circ} 3$.

No pudo menos de sorprender al exponente semejante novedad inesperada pues habiendo determinado V.M. en el artículo 9 de la Real cédula citada, que la prioridad de las pretensiones se regulase por la fechas de la presentación de los memoriales y en caso de presentarse varios en un mismo día, decidiese la suerte, parecía que por todas razones debía alcanzar la preferencia su Primo no habiendo concurrido otros pretendientes entonces según acredita la $\mathrm{Fe}$ de presentación del memorial indicado con el $n^{\circ} 3$ y resultará también de la combinación de las fechas así de los memoriales presentados por los jóvenes agraciados en las Plazas, como de las que se hallen en las certificaciones con que los acompañarían. Y por lo mismo se convence el reprensible exceso del virrey en haberse dispensado a su arbitrio de la observancia de un orden y regla tan equitativa y prudente que remueve toda odiosa desigualdad y acepción de personas opuesta a los sanos principios de política y buen gobierno.

Esta indiscreta facilidad de sacrificar la mente y letra de la soberana resolución de V.M. a las miras oficiosas de la autoridad o del favor, no puede ser ni más contraria a las sabias intensiones de un gobierno zeloso e ilustrado, ni más funesta para el establecimiento mismo en el tiempo que importa más la severa y escrupulosa observancia de las reglas, si se ha de organizar y consolidar con la perfección y firmeza conveniente. No se ocultan a la superior penetración de V.M. los males que proceden de tan viciosa raíz, pues al paso que en los primeros principios se da un ejemplo pernicioso de desorden y escándalo por condescendencias ajenas de la circunspección de un Ministro en que deposita V.M. toda su confianza, se desvanece sucesivamente la idea de veneración y respecto con que deben ser consideradas las reglas y las leyes santas y saludables de un establecimiento público que tiene tanto influxo en el honor y progreso de las Letras, en la educación de las primeras clases del Estado y en la prosperidad común.

Ni son de inferior orden los perjuicios gravísimos del escandaloso trastorno que acaba de indicarse, si se examinan los sabios fines de la nueva y benéfica institución con que V.M. ha querido consultar la felicidad y adelantamientos de unos vasallos que le merecen todo amor y cuidado a proporción de su inmensa distancia del trono. Porque al observar establecida una desigualdad opuesta diametralmente a las miras y prudentes designios 
de V.M. y sustituidos los títulos del poder, el favor, la amistad y otros semejantes proscritos por la razón y por las leyes a los justos y sencillos de la precedencia del tiempo o de la suerte, cómo no se han de entibiar y desaparecer de todo punto los estímulos eficaces de la juventud estudiosa que tantas ventajas proporciona al Estado y a las familias considerándose privada de un derecho concedido indistintamente a los individuos de la clase distinguida, pero viciado y convertido a fines siniestros por ciertas deferencias y respetos personales dignos de severa censura? Para evitar pues tan peligrosos males de que el exponente ha tenido la desgracia de ser la primera víctima: Suplica a V.M. que en consideración a los hechos y razones expuestas, se digne declarar a favor de su Primo Don Felipe Camilo Tupa Yupanqui las preferencias en la obtención de una de las dos plazas referidas del nuevo colegio de Granada, dando por nulos en caso necesario los nombramientos acordados por el virrey, a quien se haga entender el desagrado que ha causado a V.M. tan extraña y calificada contravención, y mandando expedir las órdenes correspondientes para que con arreglo al capítulo 8 de la Real cédula de erección se costee de los fondos del colegio su habilitación y embarque. Y quando V.M. no tenga a bien acceder a esta justa solicitud, dígnese a lo menos agraciarle con una de las dos plazas que se reservó por el capítulo 26 para conferirlas a los que mereciesen ser distinguidos con tan honroso testimonio de su soberana piedad y benevolencia: que en ello recibirá V.M.

Madrid 7 de mayo de 1793 en virtud de poder: Francisco Ximenez Sarmiento"

Lo que primero llama la atención en esta carta del defraudado don Bartolomé Mesa, es que recurra y se dirija al rey por medio de un apoderado en Madrid y no por la vía acostumbrada, lo que se entiende visto el contenido de la carta. No era el primero en hacerlo, pero tener un apoderado en Madrid suponía dinero y buenas relaciones. Se vale esta vez de su grado militar y no de comerciante como lo había hecho en su solicitud primera. El tono indignado es de denuncia violenta de la actitud del virrey (reprensible exceso, viciosa raíz, odiosa desigualdad) a quien acusa radicalmente de desobediencia. Se vuelve a veces aleccionador cuando contempla las consecuencias morales en la juventud de tales desvíos de la ley, y particularmente audaz al terminar cuando opone su “justa solicitud" al eventual rechazo del rey. Aquí se trata de una solicitud personal, pero la violencia del tono deja traslucir una posible rebelión de más amplitud. Se percibe todo el orgullo, la conciencia de pertenecer a la "clase distinguida", pero al mismo tiempo la aparente ingenuidad del descendiente de los incas. ¿Ignoraba los vínculos del oidor con la aristocracia peninsular? ¿Pensaba realmente que el rey anularía la decisión del virrey?

Es obvio que la esperanza era grande: por primera vez en el Perú la Corona parecía colocar de veras a los nobles indígenas en un pie de igualdad con los otros nobles

(17) Fray Antonio Garro, en su Representación... habla de 200 pesos y de los abusos de los apoderados en Madrid (Medina, 1904, t. III: 547-548). 
americanos ya que hasta entonces lo más que se había podido hacer era crear dos colegios de caciques o reservarles una tercera o cuarta parte de los seminarios, siendo éstos teóricamente destinados a los pobres. En una sociedad donde la preeminencia era tan importante, los nobles indígenas estaban a menudo confrontados a la humillación de verse colocados con los pobres o los huérfanos (18). Si ya en el siglo XVIII las puertas de las universidades no les estaban cerradas, siempre era con la "debida separación" y no aparece ningún nombre indígena en las listas de alumnos que se conservan. Ahora se trataba de un proyecto de educación en España, cerca de la soñada protección real que en sus cédulas no establecía distinción entre criollos e indígenas; había que aprovechar la situación, cogerse a la palabra.

\section{DON BARTOLOMÉ MESA INCA YUPANQUI, INDIO ILUSTRADO}

No deja de llamar la atención del lector la soltura y la lógica de don Bartolomé Mesa en su carta. Sigue una pauta que le permite, después de presentarse y exponer el objeto de su solicitud, hacer alarde de sus conocimientos, oponiendo lo antiguo a lo moderno, refiriéndose en términos jurídicos a una lectura precisa de la cédula. Continúa acusando violentamente al virrey ahora en términos de moral y acaba con una súplica. Todo en el estilo altanero de quien sólo pide justicia. También es interesante reparar en la penetración de las ideas de la Ilustración en el discurso del solicitante. Sus aserciones sobre el proyecto real corresponden con el planteamiento de un Toribio Rodríguez de Mendoza, Rector de San Carlos a partir de 1785 y gran reformador de los estudios del convictorio. Es evidente que don Bartolomé, cuando evoca "una filosofía caprichosa y llena de sutilezas vanas" se refiere a la filosofía aristotélica, calificada de "despótica" por don Toribio (Eguiguren, s.f., "Informe de D. Toribio Rodriguez Mendoza... ”: 718), que se siguió enseñando exclusivamente durante los dos siglos de dominación española, puesto que según Eguiguren fue sólo a partir de 1767 cuando el pensamiento de Aristóteles dejó de ser el único enseñado en San Marcos (Eguiguren, s.f.: 306). Cuando habla de "los buenos y sólidos principios de los Estudios modernos" se refiere al predominio de la razón sobre la tradición, consabido tema de debate de la época. Don Bartolomé Mesa Túpac Yupanqui adopta aquí las ideas más modernas sobre la educación, ideas que en esos años no eran admitidas por todos, ni mucho menos, en el Perú, sino más bien combatidas por el poder eclesiástico y que tampoco convencían a todos los oidores de la Audiencia de Lima, ideas en fin que el nuevo Rector del real convictorio de San Carlos se esforzaba en incorporar a su plan de estudios paulatinamente frente a una sociedad limeña muy apegada a la tradición. Una persona, sin embargo, apoyaba al Rector en estos esfuerzos: don Ambrosio Cerdán a quien don Bartolomé acusa, implícitamente en su carta, de colusión con el virrey.

Este indio noble, que parece tan enterado de lo que se hacía en el colegio faro de la corte virreinal y sobre todo tan apegado a nombrarlo, formaría parte de la minoría

(18) Un ejemplo es el sitio señalado por el cabildo a los alumnos del colegio del Príncipe para asistir a las fiestas y corridas de toros: lo único que se propuso, no sin dificultad, al Rector fue compartir "con separación" la esquina atribuida a los Huérfanos (las otras esquinas estaban atribuidas al colegio que fue de San Martín, o sea al convictorio de San Carlos, al de Santo Toribio, y al comisario de los toros) (Inca I, 1923: 849). 
culta, que tenía acceso a lecturas prohibidas (19) venidas de Europa, una minoría susceptible de complot. En 1809 aparece su nombre entre los arrestados de una sospechada conspiración en Lima (Eguiguren, s.f.: 884) aunque no entre los reos (Eguiguren, 1957) (20). Su calidad de representante de los indios en Lima parece estar al origen del incidente ya que no aparece ninguna acusación directa. Sin embargo el proceso revela que algunos de los supuestos subversivos trataban con él. De momento, en 1793, su alegato contra el virrey, para ganarse la comprensión del monarca ilustrado, retoma los conceptos de razón, de progreso, de prosperidad común por el bien del Estado, gracias a la educación. Cabe tener en cuenta que la educación superior y la enseñanza de las ciencias útiles era una de las reivindicaciones recurrentes de los indígenas.

En el discurso de don Bartolomé Mesa, el convictorio de San Carlos ocupa un lugar preeminente pero "sin embargo de estos útiles progresos" mejor todavía le parece el colegio de Granada, opinión que comparten con él peninsulares y criollos en América, ya que don Ambrosio Cerdán amigo de Rodríguez de Mendoza (Vargas Ugarte, 1970: 88) y muy implicado en la evolución de San Carlos, también quiere mandar a sus dos hijos a España. Sin embargo, en el convictorio carolino se estudiaban ya todas las ciencias útiles incluida la Nautica (21). Se imponía la idea de que en España los maestros eran mejores, la enseñanza más adaptada a la formación de los futuros altos funcionarios y tal vez se contemplaba la posibilidad de poder reformar mejor la enseñanza en el Perú a raíz de esta (22) experiencia.

Ahora bien, si tiene razón don Bartolomé Mesa en lo que toca al arbitrio del virrey, merece la pena examinar sus argumentos. Son de doble índole: la injusticia de que fue víctima su primo que, según él, cumplía todos los requisitos para lograr una de las dos becas, y las consecuencias morales y políticas que acarrea la no obediencia a la palabra real, lo que equivale a denunciar la arbitrariedad y la colusión de la persona del virrey. Estos argumentos se desarrollan a partir del no respeto de la prioridad.

\section{DON FELIPE SANTIAGO INCA TÚPAC YUPANQUI, ALUMNO DEL COLEGIO DEL PRÍNCIPE}

Varios documentos del Archivo General de la Nación además de los que fueron publicados en la revista Inca permiten seguir algunos pasos de este descendiente de los incas. En primer lugar es cierto que don Felipe Túpac Yupanqui fue alumno del colegio de caciques del Cercado ya que su ingreso consta en el registro de dicho colegio (23)

(19) Montesquieu, Marmontel, Raynal, la enciclopedia, fueron prohibidos, recogidos y quemados por real orden de 1785 (Medina, 1904, "introducción” XC, retomado en Eguiguren, s.f.: 158).

(20) Sólo aparece mencionado como formando parte de una red de sospechosos (t. II: 150). Agradezco a Joelle Chassin haberme comunicado este texto.

(21) Se deduce por lo menos del ya citado "Lamento métrico". Véase nota 9.

(22) En 1795 Rodríguez de Mendoza pidió la reforma de los estudios de matemáticas y de historia eclesiástica en el Real convictorio (Eguiguren, s.f.: 884).

(23) Este libro fue publicado en la revista Inca en 1923 sin nombre del transcriptor ni localización y dicho documento que pudo pertenecer al ramo de Temporalidades del AGN se extravió. 
donde se puede leer el 7 de marzo de 1780: "Felipe Santiago Túpac Yupanqui cacique de San Geronimo, entró" pero seis meses después se lee que "se fue a convalecer". No queda huella de que haya vuelto, es posible que sea una simple omisión, pero, en general, por esas fechas se solían apuntar salidas y vueltas.

El colegio del Príncipe había sido fundado en el Cercado de Lima por el virrey Esquilache como consecuencia de la campaña de extirpación de idolatrías que se había iniciado a principios del siglo XVII en el Perú. Los jesuitas se encargaron de la dirección y de la educación que se dispensaba a los hijos de caciques y nobles. Lo hicieron más con vistas a su conversión, de la que dependía la de los indios del común, que a alzarlos a la altura de los españoles y criollos que formaban la élite de la sociedad colonial. Si bien al principio los alumnos pudieron seguir clases de gramática hubo un momento en que decayeron las condiciones de enseñanza de los indios. Después de la expulsión de la Compañía, siguió funcionando el colegio y conoció entonces una serie de reformas que correspondían a las inquietudes de la época. Hubo una revalorización de los estudios con la creación de una y luego otra aula de latinidad, enseñanza de la Historia, y más contactos con la Universidad. Bartolomé Mesa parece más bien valorar el que su primo haya sido alumno allí, por lo menos no lo calla, lo que no significa forzosamente que el colegio tuviera buena reputación, puesto que necesitaba para su primo un certificado elogioso que el Rector Bordanave le concedía fácilmente.

Normalmente los alumnos del colegio del Príncipe no podían entrar antes de cumplir los doce años (existen casos donde se dice claramente que el alumno fue rechazado por no tener la edad requerida. Sin embargo hubo algunas excepciones, en realidad muy pocas en el espacio de casi dos siglos: uno que "entró muy tierno" otro que fue nombrado colegial en 1797 limitándose la gracia hasta que entre en edad de diez años y otro que entró en 1799 a los nueve años). Ninguna consideración particular acompaña la entrada de don Felipe Camilo Túpac Yupanqui. Sin embargo, si consideramos que excepcionalmente pudo ingresar a los nueve años, en 1792 tendría veintiuno a lo mínimo. El límite de edad era de diez y ocho para pretender entrar en el colegio de Nobles Americanos de Granada: si bien se omitió exhibir los documentos justificativos de su Nobleza, no fue porque ya los había presentado al superior gobierno o por la notoriedad de su nobleza como lo afirma su altivo primo, sino porque tales documentos constaban de su partida de bautismo y por lo tanto lo eliminaban inmediatamente.

Otro elemento es la presentación de los certificados médicos, dos documentos permiten sospechar que sean de conveniencia: el registro del colegio que declara su ausencia para convalecer a los seis meses de entrar y una declaración del Rector Juan de Bordanave en 1790, según la que "Felipe Santiago Camilo Tupayupanqui cacique de San Geronimo de Atunjauja, recibido en 1780, ha estado enfermizo y a aprendido a leer escribir y contar, la gramática, está estudiando Artes en Santo Tomás los que empezó por abril de 1789 acabará por el mes de mayo de este año y se dará parte a este juzgado cuando tenga las conclusiones de todas artes" (A.G.N., Temporalidades, colegios, legajo 171). Esta declaración no precisa dónde aprendió a leer, escribir y contar etc., aun si sobreentiende que fue en el colegio del Príncipe, el cual tenía todo interés en contar entre sus alumnos al brillante inca. La mención de su estado enfermizo puede estar aquí para justificar la ausencia de notas y apreciaciones en los cuadernos del colegio. Como 
se colige de los términos en que va escrita, se trata de una declaración del Rector ante un juzgado. El licenciado Juan de Bordanave había sido acusado de una pésima administración del colegio, de dejadez en la educación de los colegiales, de falsificación de las cuentas, etc.: una visita del fiscal en 1791 revela que el colegio carecía de todo, que las habitaciones estaban llenas de inmundicias que los colegiales dormían en unos pellejos y otros cargos graves como el de reservar el Rector para su propio servicio los dos esclavos del establecimiento (A.G.N., Temporalidades, colegios, legajo 171).

Lo interesante es que sólo dos alumnos declaran a favor de Juan de Bordanave mientras que todos los demás y sus padres coinciden en denunciar una situación insoportable, en particular la inadecuación entre lo que declaraba el Rector y la realidad, precisamente en lo que se refería a vestidos (usados, heredados inmediatamente del compañero muerto sin considerar medidas ni tamaños, o simplemente ninguno). De los dos testimonios, el primero es el de Santiago Tupayupanqui que declara haber recibido cinco vestidos (los otros dicen haber recibido uno en cinco años) haber sido bien alimentado y bien cuidado (A.G.N., Temporalidades, colegios, legajo 171). Pero es el testimonio de alguien que ha dejado el colegio, por lo menos desde hace dos años y muy posiblemente diez.

Juan de Bordanave además de Rector del colegio de caciques era canónigo de la catedral y catedrático de Retórica en San Marcos, por tanto un personage que podía ser influyente. Sus problemas empezaron en 1790 y concluyeron con su obligada demisión del rectorado en enero de 1795 , después de un largo pleito, lo que permite pensar que su culpabilidad quedó realmente manifiesta, dada la posición social que ocupaba. Este período coincide en gran parte con la solicitud de don Bartolomé Mesa en nombre de su primo para lograr una beca en el seminario de Nobles Americanos de Granada.

Es muy verosímil que el testimonio de don Santiago Felipe Tupayupanqui a favor de don Juan de Bordanave que resulta tan disonante de los otros haya sido de conveniencia y que don Bartolomé de Mesa pensara aprovechar la relación al parecer cordial, si no es más, con el Rector para apoyar su solicitud.

Por otra parte don Bartolomé insiste una y otra vez, en que su primo está estudiando en el convictorio de San Carlos, insinuando que allí se graduó, pero tanto el certificado de fray Cipriano Cavallero como la declaración de don Juan de Bordanave dicen que estudió filosofía en Santo Tomás, colegio de los Predicadores de menos prestigio y menos al día que el convictorio de San Carlos.

Un discurso pronunciado por los diputados americanos en Cádiz contra el artículo 22 del proyecto de constitución, publicado por Eguiguren, aclara lo que atañe a la educación de las diferentes castas en Lima:

"Para los estudios mayores hay a más del seminario de Santo Toribio, el colegio de San Carlos, cuyos estudiantes están uniformados; No se admiten en ellos a las castas pero sí a todos los que son reputados por blancos; Hay también varios colegios y universidades pontificias pertenecientes a las órdenes religiosas, en los que se enseñan la Filosofía y Teología a los jóvenes de toda clase, color y nacimiento, los cuales no sean uniformados". 
Esto corrobora que don Camilo Santiago haya seguido sus estudios en Santo Tomás y no en San Carlos como lo insinúa su primo. Sin embargo las fechas de mayo — su examen — y agosto — la solicitud — permiten la hipotésis de que haya seguido allí otras clases después de lograr su título en el colegio dominicano, siendo reputado por blanco por su nobleza y tal vez su riqueza. Este colegio fue fundado por el virrey Amat en 1770, reuniendo en él los dos colegios largo tiempo rivales de San Martín y de San Felipe y San Marcos. En 1822 se le incorporó el del Príncipe, mezclando así la nobleza americana sin distinción (Guía política eclesiástica y militar del Perú para el año 1841 Lima 1841). En 1792 todavía había separación. Quedan por estudiar los vínculos que existían entonces entre el convictorio de San Carlos y el colegio del Príncipe, pero es posible que desde entonces caminara la idea de integrar a los nobles indios instruidos al real convictorio, en este caso don Bartolomé Mesa pudo participar del intento introduciendo a su primo. El caso es que en San Carlos se educaba de la manera más moderna lo mejor de la sociedad limeña y esto era lo que a él le importaba.

\section{LA “PRECEDENCIA” ESPEJO DE UNA DOLOROSA INFERIORIDAD}

Todos estos detalles ponen de relieve el afán de reconocimiento y de igualdad que tenían los indios nobles, y las dificultades que eran las suyas aun si mantenían relaciones con los criollos, para hacerles competencia. Lo que también es digno de reparo en esta carta al rey es que en ningún momento insinúa que el hecho de ser indio haya podido perjudicar a su primo, al contrario razona como si los descendientes de los incas fuesen obviamente iguales a los nobles criollos y españoles, como si el sueño del Inca Garcilaso fuese realidad. Lo interesante es que esta manera altanera y absoluta de negar la posibilidad de cualquier diferencia, encuentra su justificación en el discurso oficial de la Corona.

El disimulo, la mentira que se perciben en el caso de don Bartolomé Mesa suelen ser las armas de los dominados. Ahora bien, tampoco del lado de los dominantes se jugaba limpio. Oficialmente desde el decreto real de 1767 se consideraba a los nobles indios "hábiles para gozar los empleos eclesiásticos o seculares, gubernativos, políticos y de guerra que piden limpieza de sangre y que se acostumbraban conferir a los nobles hijos dalgos de Castilla..." (Auto de noviembre de 1770, Inca I, 1923: 862). Pero en el Perú los frenos a la aplicación de esta ley podían más que la real palabra. La rebelión de Túpac Amaru acababa de confortar la desconfianza hacia estos nobles. En 1797, por ejemplo, se le niega al cacique Cevallos la confirmación del empleo de Sargento mayor de Naturales "por haberse suprimido estas milicias y no considerarse conveniente instruir en el manejo de arma y evoluciones a los Yndios" (A.G.I., Secretaría de guerra, 7124, exp. 47), lo que contradice el decreto de 1767 y las constituciones de 1792 del seminario de Nobles Americanos de Granada que no excluyen a los Indios de la carrera militar. Por tanto se entiende que don Bartolomé Mesa se dirija al rey como último recurso y lo haga oponiendo sistemáticamente "la benignidad, el digno y laudable celo, las sabias intensiones de un gobierno zeloso e ilustrado, las leyes santas y saludables, la nueva y benéfica institución, los prudentes designios" del rey al "reprensible exceso, la desigualdad, el desorden, el escándalo, el favor, la amistad”, propios del virrey. 
Naturalmente el mayor argumento que tiene es la prioridad en el tiempo con que presentó su solicitud. Con él quiere borrar las objeciones que con razón se le podían oponer. Pero hay más: esta prioridad otorgada al que llegue primero, la precedencia del tiempo o de la suerte le parecen la condición de la verdadera igualdad, la que descarta las amistades, el favor y todas clases de colusiones dentro del ámbito criollo, y la verdad es que esta nueva decisión, de ser aplicada, hubiera sido una verdadera revolución.

Así, aun sin denunciar directamente la discriminación de que son víctimas los indios, su alegato remite constantemente a la noción de igualdad, de derecho concedido indistintamente a una nobleza u otra.

Una de las humillaciones que sufrían los nobles indígenas era precisamente la de ser tratados de "indios" lo que les podía confundir con los indios del común a quienes ellos mismos despreciaban. No perder los privilegios concedidos era la mayor preocupación de los caciques y nobles descendientes de los incas, particularmente en esa época y cabe decir que incluso éstos consideraban a aquéllos como gente ordinaria (24).

Un buen ejemplo es el de Doña María Joaquina Ynca que, en los años 90, multiplicaba en la corte de México las gestiones para lograr una pensión y ser tratada con los honores y respeto debidos a su linaje que, según ella demuestra, remontaba también al gran Túpac Yupanqui. El voluminoso expediente remite reiteradamente a los derechos y privilegios otorgados por Carlos $\mathrm{V}$ a los descendientes de los incas en 1545 (C.D.I.H.I: 300-305): tratamiento de personas Reales, escudo de armas, solios "la facultad de vestir el insigne toysón de oro, como blasón el más distinguido en las monarquías de Europa con la que en todos los dominios representan la misma Real persona y demás franquezas que creyeron conducir al descargo de su real conciencia, unión de entrambas coronas, buen gobierno paz y quietud de esos y aquellos dominios..." El tono orgulloso, a veces hasta irrespetuoso, es bastante parecido al de don Bartolomé Mesa. Su solicitud revela que si bien en el siglo XVII, los abuelos de Doña Joaquina pidieron la confirmación de estos derechos (autos de 1639 y 1652 en Lima), nadie se preocupó por hacerlo en el siglo XVIII hasta la fecha, y tales derechos y privilegios son juzgados exorbitantes en 1800 por la Audiencia y el virrey (A.G.I., México 2346) de Nueva España, en particular el que otorgaba a estos nobles la posibilidad de formar un Real Acuerdo con dos oidores en caso de discrepancia con el virrey, o sea la posibilidad de contravenir a sus decisiones. Otro elemento digno de mencionar en este expediente es que en las partidas de matrimonio y bautismo de sus hijos Dña Joaquina se dice española (A.G.I., México 2346, fol. 92) (25).

La noción de "precedencia" con su cortejo de humillaciones, tan importante en aquella Lima colonial que vivía al ritmo de numerosas fiestas públicas, era la que regía todas las relaciones, imperaba en la imagen que cada uno de los grupos sociales tenía

(24) En el voluminoso expediente de D(oñ)a María Joaquina Inca una reclamación de sus antepasados en 1656 por haber sido convocados a la mita completan su argumento de esta forma: "Además de que no se ajusta el que no compreendiéndose en d(ic)ho bando los caciques gobernadores que es gente ordinaria, los que son de mayor privilegio como los suplicantes sean compreendidos en el d(ic)ho bando" (A.G.I., Mexico 2346, superior gobierno 1796).

(25) En la partida de matrimonio la palabra "española" está claramente escrita y en la de bautismo de su hijo fue añadida, supuestamente a petición suya. 
de sí mismo. La participación en ellas de éstos reflejaba su posición en la jararquía. En la Representacion verdadera...en 1750, fr. Antonio Garro, en nombre de los indios, lamenta que en la fiesta que tuvo lugar en Lima en 1748, les haya "cabido en ellas el último lugar, como siempre les cabe en todo". A las fiestas sólo se podía asistir desde un sitio atribuido según su rango. (Bernales in Historia y cultura,1969: 24)

La importancia del traje era enorme para distinguir los grupos sociales y étnicos, y en particular en los colegios mayores. El discurso de los diputados a Cortes ya citado después de mostrar que los colegios que aceptaban a los indios castas y morenos no usaban uniformes concluye diciendo:

“... de lo que se deduce en primer lugar que toda la distinción y preminencia que se observa entre los estudiantes blancos sobre los de diversas clases que componen esta ciudad, sólo se funde en el trage. Esta es una distinción política.."

Precedencia de los nobles indios sobre los caciques, de los nobles criollos sobre los nobles indios, de los peninsulares sobre los criollos... en una ciudad cuyo palacio de gobierno era asediado cotidianamente por una multitud de solicitantes.

Así, cuando el Mercurio Peruano publicó el decreto real que fundaba el colegio de nobles americanos de Granada, lo acompañó de un comentario más que entusiástico, calificando la decisión real de "monumento más glorioso que inmortalize el feliz Reynado del Augusto Carlos IV" ya que "Se olvidará hasta el nombre de esta odiosa rivalidad que en perjuicio y deshonor del Estado pretende encontrar diferencia entre los hijos de un mismo Padre...". Aludía esencialmente, claro, a la rivalidad entre criollos y peninsulares.

Tal vez estos motivos de orgullo para unos y de vejación para otros expliquen ciertas reacciones de unos y otros a lo largo de los siglos coloniales en lo que a educación atañe.

Los colegios de caciques fueron creados para educar las élites indígenas, eran colegios reales que ostentaban las armas reales junto con la mascapaicha en sus fachadas (Dean, 1999: 152); se les concedió un uniforme (Alaperrine-Bouyer, 1999), compromiso entre la indumentaria española y la indígena, uniforme que pudieron conservar a duras penas contra el aviso del Real Acuerdo que siguió la partida de Esquilache; tenían derecho a ocupar un lugar distinguido en las fiestas públicas pero se tardó mucho en concederles una esquina de la plaza que debieron compartir "con separación" con los niños expósitos (26). Además la administración de los jesuitas poco a poco introdujo alumnos criollos y peninsulares tanto en el colegio del Cuzco como en eldel Cercado de Lima. Los nobles indios protestaron claramente contra esta mezcla que decían ser en perjuicio de sus hijos (AGI, Lima, 169; de la Puente Brunke, 1998; Alaperrine-Bouyer, por publicar):

"siendo assí que sólo esto tienen en este reyno por grandeça y consuelo nuestro, merced de tanta ymportancia..."

(26) Véase supra, nota 18. 
Más tarde, cuando Carlos III quiso atraer a los nobles criollos a España destinándoles 40 plazas en el seminario de nobles de Madrid (Olaechea Labayen, 1963: 213), los americanos no se precipitaron y muy pocos vinieron, no disputaron las plazas a los indios, pero cuando Carlos IV fundó prematuramente el colegio de Nobles Americanos de Granada, entonces sí que hubo muchas solicitudes, la disputa y exclusión que conocemos.

Lo que llama la atención es que en los diferentes casos se trata de privilegio: cuando los caciques decían que sólo tenían los colegios por grandeza y consuelo no hablaban de otra cosa que de privilegio, el que los distinguía de los indios del común y les acercaba a los otros nobles que tenían sus colegios uniformados. Los hijos de criollos además de humillarles y tratarles mal, negaban por su sola presencia este privilegio. Cuando los nobles criollos se negaban a mandar a sus hijos a Madrid, temían la misma discriminación por parte de los peninsulares pero cuando se les aseguraba la exclusividad en la tentativa de Granada, entonces sí que allí veían un privilegio concedido a su clase y no pretendían que los indios nobles lo compartieran. Mezclarse con el otro, en una experiencia que pone en juego las capacidades intelectuales, pide una imagen positiva de sí mismo que los criollos no devolvían a los indios en su tierra ni los peninsulares a los criollos. La posible pretensión de don Felipe Túpac Yupanqui a fines del siglo XVIII marca una evolución: desde hacía unas décadas la enseñanza superior ya no se cerraba a los indios nobles, se había creado oficialmente una aula de latinidad en los colegios de caciques y entonces eran ellos los que se introducían en los colegios mayores. Don Felipe, completa los estudios en Santo Tomás y hasta, tal vez, logra inmiscuirse en San Carlos. Las ideas de la ilustración permitían dar estos pasos. Si estaba dispuesto a marcharse a España, era aparentemente porque pensaba que allí los estudios serían mejores pero también porque se trataba de medirse con los nobles criollos con la vara de la beca de gracia, y tal vez porque creyera en la protección del Rey, en la sinceridad de la palabra real que oficialmente no establecía diferencia entre sus vasallos.

Pero también cabe preguntarse: ¿Creía realmente su inteligente primo en la posibilidad de ganar contra el virrey y la aristocracia criolla? Ya más de cuarenta años antes, La Representación... que el hermano Calixto de San Joseph Túpac Inga (Medina, 1904: 542 a 553) remitió directamente al rey, "a costa de riesgos y peligros, aún de la propia vida" (Medina, 1904: 546) después de un largo viaje clandestino, llevaba la misma idea que la pésima condición de la Nación india se debía sólo a la tiranía de los virreyes y sus funcionarios. ¿No había servido de lección el infeliz desenlace de la aventura de este lejano pariente de don Bartolomé que conoció la prisión y el destierro? ¿o sólo quería éste manifestarse en una especie de desafío, afirmar su pretensión a la igualdad de todos los nobles americanos indios y criollos, recordar a la faz del mundo los olvidados privilegios de los descendientes de los Incas?

\section{CONCLUSIÓN}

El proyecto del colegio de nobles americanos de Granada que no llegó a funcionar $-\mathrm{y}$ precisamente porque no llegó a funcionar-, además de poner de manifiesto la existencia paralela de diferentes redes de poder: la de los criollos y la de los indios ricos que compiten desigualmente, evidencia el juego entre los diferentes 
discursos coloniales. El del rey, destinado a los criollos, que con pretexto de la "universal difusión de las luces" promete la igualdad a todos sus nobles súbditos que pretendan un puesto de altas responsabilidades con tal que den prueba de sus méritos y capacidades, es un discurso equitativo y generoso que disimula la desconfianza, verdadero objeto de la fundación del colegio. En realidad oculta el proyecto político de un despota ilustrado que quiere controlar mejor una aristocracia frustrada en sus esperanzas y mejorar la administración de las colonias en provecho de la metrópoli. Lo que se lee y deduce de los 47 artículos es la voluntad de equiparar los estudios, de dar a cada uno la oportunidad de salir con un puesto honroso y por tanto de satisfacer el orgullo herido de los criollos, pero lo que no se dice sino de manera ambigua es la imposibilidad en que estarián luego las futuras élites de ejercer en sus propios países.

Cuando se dirige a los nobles indios, el rey les garantiza la igualdad con los otros nobles. Ha sido el discurso de la Corona, desde los principios de la colonia, un discurso de protección que garantiza una buena educación a los nobles y caciques y se ha ido repitiendo en múltiples cédulas a lo largo de los siglos de colonización. Los privilegios otorgados por Carlos V a los descendientes de los incas en 1545, como lo hemos visto les fueron confirmados varias veces, pero no queda rastro de que formaran jamás un Real Acuerdo para contrarrestar las decisiones de un virrey. En el siglo XVIII, otras repetidas cédulas les aseguran su integración en los colegios y seminarios y su derecho a ocupar, ellos también, puestos honrosos, y lo que se deduce de las constituciones del colegio de Granada es que no se les puede excluir de ninguna carrera. La realidad resulta ser muy distinta. Y el real discurso parece cerrarse como un círculo que dejaría fuera esta realidad, como si bastara su enunciación al famoso "descargo de la real conciencia".

Sin embargo los nobles indios parecen seguir creyendo en la palabra de la Corona, en la infalibilidad y el amor de un monarca ecuánime y justo, acusando a los virreyes de no cumplir las leyes. El pretexto de la lejanía del rey sirve a las dos partes: al rey para quitarse toda responsabilidad, a los indios para seguir creyendo que son menos desvalidos de lo que parece. Esta fe simulada o real les permite seguir pidiendo privilegios, pensiones, honores, y manifestando con altivez su nobleza. A fines del siglo XVIII, a pesar de todo no se han doblegado. El discurso del noble indio sigue siendo el del entonces prohibido Inca Garcilaso en su reivindicación de igualdad. Pero al mismo tiempo es también el discurso de mentiras y disimulaciones de los dominados. Don Bartolomé Mesa Inca Yupanqui a este respecto es ejemplar.

\title{
Referencias citadas
}

\author{
ARCHIVOS: \\ A.G.I., Archivo General de Indias (Sevilla) \\ Indiferente general, 1613, 1619, 1620, 1621 \\ Secretaría de guerra 7104 \\ México 2346 \\ A.G.N. Archivo General de la Nación (Lima)
}


Temporalidades, colegios, leg. 171

A.N.S. Archivo Nacional de Santiago de Chile

Fondo Jesuita del Perú, vol. 372

ALAPERRINE BOUYER, M., 1999 - Comment policer les nobles indigènes. Les stratégies d'une éducation au service du pouvoir colonial. In: Transgressions et stratégies du métissage en Amérique coloniale: 201-222; Paris: PSN.

ALAPERRINE BOUYER, M., (por publicar)-Saber y poder. In: Actas del coloquio internacional Cuzco, 2000 .

BAREA FERRER, J. L., 1977-1978 - El palacio de Carlos V en 1793 y el proyecto de su conversión en colegio militar de nobles americanos. In: Anuario de Historia Moderna y Contemporánea, $\mathbf{N}^{\circ} 4$ et 5: 27-49; Granada: Universidad de Granada.

BERNALES BALLESTEROS, J., 1969 - Fray Calixto de San José Túpac Inca, Procurador de los indios y la 'exclamación' reivindicacionista de 1750. Historia y cultura, $\mathbf{N}^{\circ}$ 3: 4-35; Lima.

C.D.I.H.I. (Colección de Documentos Inéditos para la Historia de Iberoamérica), 1925-1932 Tomo II: 301-308; Madrid, 14 tomos.

CRUZ, Sor J. I. de la, 1994 - Respuesta a Sor Filotea de la Cruz. In: Obras completas Tomo IV (Mendez Plancarte): 440-475; México: Fondo de Cultura Económica.

DEAN, C., 1999 - Inca Bodies and the Body of Christ, 288p.; Duke University press.

DIAZ TRECHUELO, M. L., 1972 - Españoles Americanos en los colegios Mayores del Sacromonte y de san Bartolomé y Santiago de la Universidad de Granada. Siglos XVIII y XIX. In: Quinto Congreso Internacional de Historia de América: 497-534; Lima.

EGUIGUREN, L. A., s.f. - Diccionario histórico bibliográfico de la Universidad de San Marcos, tomo III, 1302p.; Lima.

EGUIGUREN, L. A., 1912 - Catálogo Histórico del Claustro de la Universidad de San Marcos 1576-1800, 89p.; Lima: Imprenta del Progreso editorial.

EGUIGUREN, L. A., 1950 - Toribio Rodriguez de Mendoza, 20p.; Lima.

EGUIGUREN, L. A., 1957 - Guerra Separatista; Buenos Aires.

GONZALBO AIZPURU, P., 1989 - La educación popular de los jesuitas, 344p.; Mexico.

GUERRERO CANO, M. M., 1996-1997 - Un dominicano en el colegio de nobles americanos de Granada. Familia y genealogía de Juan Clemente Martínez Saviñón. Trocadero, No 8-9: 383-400; Cádiz.

GUÍA POLÍTICA ECLESIÁSTICA Y MILITAR DEL PERÚ PARA EL AÑO 1841, 1841, Lima.

INCA I, 1923, Lima.

INCA GARCILASO de la VEGA, 1960 - Comentarios reales. In: Biblioteca de Autores Españoles, t. CXXXIII: 395p.; Madrid: Ediciones Alas .

KONETZKE, R., 1953 - Colección de documentos para la historia de la formación social de Hispanoamérica, 671p.; Madrid: CISC.

LAVALLÉ, B., 1993 - Del indio al criollo. Evolución de una imagen colonial. In: Las promesas ambiguas. Criollismo colonial en los Andes: 45-61; Lima: PUCP-Instituto Riva-Agüero.

MEDINA, J. T., 1904-1907 - La imprenta en Lima, tomo III; Santiago de Chile: En casa del Autor.

MÉNDEZ, C., 1993 - Incas sí, indios no: apuntes para el estudio del nacionalismo criollo en el Perú, 36p.; Lima: I.E.P. Documento de trabajo $\mathrm{N}^{\circ} 56$, serie Historia $\mathrm{N}^{\circ} 9$.

MERCURIO PERUANO, 1792, Lima.

O'PHELAN, S., 1995 - La gran rebelión en los Andes: de Túpac Amaru a Túpac Catari, 237p.; Cuzco: CBC-Petroperú. 
OLAECHEA LABAYEN, J. B. 1963 - El Real Colegio de Nobles Americanos de Granada. Missionalia Hispánica, año XX, $\mathrm{N}^{\circ}$ 59: 211-237; Madrid: CSIC.

PUENTE BRUNKE, J. de la, 1998 - 'Los vasallos se desentrañan por su rey': Notas sobre quejas de curacas en el Perú del siglo XVII. Anuario de Estudios Americanos, LV-2: 459-473.

RIEU MILLAN, M.-L., 1979 - À propos de la trahison de l'inca Yupanqui, commissaire de guerre de la place de Jaca (mars-avril 1809). Caravelle, $\mathbf{N}^{\circ} 33: 49-75$.

RIEU MILLAN, M.-L., 1982 - Projet de formation des élites créoles dans la péninsule à la fin du XVIII siècle. Mélanges de la Casa de Velazquez: 199-214; Paris.

RIEU MILLAN, M.-L., 1990 - Los diputados americanos en las Cortes de Cádiz, 438p.; Madrid: CSIC.

ROWE, J. H., 1954 - Movimiento nacional inca del siglo XVIII. Revista universitaria del Cuzco, $\mathbf{N}^{\circ}$ 107: 17-47; Cuzco: Universidad nacional del Cuzco.

VARGAS UGARTE, R., 1970 - El real convictorio Carolino y sus dos luminarios, 191p.; Lima. 